\title{
Effects of pharmacomechanical therapy on late complications in deep venous thrombosis
}

\begin{abstract}
Introduction: We investigated the effects of pharmacomechanical therapy (PMT) on postthrombotic syndrome; which is a late complication in patients with acute and subacute iliofemoral deep venous thrombosis (DVT).

Method: A total of 25 (14 males, 11 females) patients; who were diagnosed with acute and subacute iliofemoral DVT and treated in the cardiovascular surgery clinic of Elazığ Training and Research Hospital from September 2016 to November 2018, were evaluated retrospectively by using data in the hospital's digital archiving system. The effects of PMT applied to the patients were evaluated on the development of post-thrombotic syndrome and venous reflux as the late complications.
\end{abstract}

Results: No complications occurred in patients during the intervention and therapeutic processes. After the treatment, patency and flow were achieved in $92 \%$ of the patients and significant reductions in the subjective complaints were observed in $88 \%$ of the patients. Maintained patency ratios of $92 \%, 84 \%$, and $80 \%$ were confirmed in the first month, the first year, and the second year, respectively, by venous doppler ultrasonography. Postthrombotic syndrome did not develop in $80 \%$ of the patients clinically.

Discussion: We suggest that PMT is a favourable treatment option for the prevention of the development of post-thrombotic syndrome and venous reflux as the late complications in acute and subacute proximal DVT patients.

Keywords: DVT, pharmacomechanical therapy, venous reflux, post-thrombotic syndrome
Volume 13 Issue 5 - 2020

\author{
Davut Azboy, Zeki Temiztürk, Fevzi Sarper \\ Türker \\ Elazı̆̆ Training and Research Hospital, Fethi Sekin City Hospital, \\ Turkey \\ Correspondence: Elazığ Training and Research Hospital, Fethi \\ Sekin City Hospital, Cardiovascular Surgery Clinic, Elazı̆̆, Turkey, \\ Email sarperturker@gmail.com
}

Received: July 16, 2020 | Published: October 27, 2020

\section{Introduction}

Deep vein thrombosis (DVT) affects one in one thousand adults annually with an annual mortality rate of $14.6 \%$. Particularly iliofemoral DVT can result in recurrent thrombus formation consequently leading to post-thrombotic syndrome (PTS) characterized by chronic venous insufficiency and ulcerations. PTS causes significant disability, impaired quality of life, and economic burden. Early thrombus removal techniques have been advocated in patients with iliofemoral DVT to improve vein patency, prevent valvular dysfunction, and reduce future complications, such as post-thrombotic syndrome and venous ulceration. ${ }^{1}$ The likelihood of PTS development is around $50 \%$ despite anticoagulant therapy in proximal DVT patients. ${ }^{2,3}$ Small-sized randomized studies suggest that the removal of an acutely formed thrombus prevents the development of PTS by preserving venous functions based on the open vein hypothesis. PTS commonly causes chronic limb pain and swelling and can progress to major disability, leg ulcers, and impaired quality of life. ${ }^{4}$

The rates of PTS despite long-term anticoagulant therapy have been reported as $28 \%$ in 5years and $36 \%$ in 12 years. ${ }^{5}$ Therefore, thrombolysis of the thrombus by thrombolytic therapy has been brought up into the agenda but it has been implemented to practice to be used via selective catheterization due to increased risks occurring with systemic administration. Thus, short-term therapy has been enabled by administering low doses of thrombolytic agents. ${ }^{6} \mathrm{~A}$ catheter can be inserted into the vein and the clot can be removed directly (mechanical thrombectomy); the clot can be broken down with medications infused into a vein in the foot or directly at the site of the clot via a catheter under X-ray guidance (PMT), or a combination of these two procedures can be applied. ${ }^{1}$ In this study, we aimed to investigate the emergence of early and late complications and the long-term efficacy of treatment for PTS applied by the administration of recombinant human tissue-type plasminogen activator (tPA) (Actilyse; Boehringer Ingelheim, Germany) via a Cleaner rotational catheter (Rex Medical, Fort Worth, TX) to patients with acute or subacute iliofemoral DVT in our clinic.

\section{Materials and methods}

Twenty-five patients; who were diagnosed with acute or subacute iliofemoral DVT and received PTS by the administration of tPA via the endovascular route by using a Cleaner rotational thrombectomy catheter (Rex Medical, Fort Worth, TX) in the cardiovascular surgery clinic of Elazı $\breve{g}$ Training and Research Hospital from September 2016 to November 2018, were included in the study. Of the patients; $13(52 \%)$ were males and $12(48 \%)$ were females and the mean age was 46.1(18-80) years. The diagnosis was made with a clinical examination and imaging with Doppler ultrasonography (USG) in all patients. The Doppler technique not only confirmed the diagnosis but also allowed the interpretation of the images and determination of the thrombus age by experienced radiologists contributing to a treatment plan. Patients with a thrombus age of younger than two weeks, patients with a venous thrombosis extending from the femoral veins to the iliac veins, and patients with no contraindications for receiving thrombolytic therapy (no recent history of surgical therapy, no history of intracranial bleeding, and not being actively treated for cancer) were included. The patients were hospitalized; anticoagulant therapy (heparin, low-molecular-weight heparin) was started, and routine blood tests were completed; then, the patients were prepared for the 
intervention. After the patients were informed about the intervention and the side of medications to be used, their informed consent was obtained.

All procedures were performed in collaboration with anaesthetists in the coronary angiography laboratory of our hospital. Under local anaesthesia and sedation, a temporary vena cava filter (Angel Catheter, $\mathrm{BiO} 2 \mathrm{Medical}$, San Antonio, TX) was placed under the renal veins via the common femoral vein of the contralateral leg. When the patient was in the prone position, a 0.35 -inch guidewire was percutaneously inserted and advanced into the popliteal vein of the leg with DVT under Doppler USG guidance. A 7F sheath was placed into the popliteal vein over the guidewire and the venograms of the extremity were obtained from this point (Figure 1). Then, the Cleaner 6F rotational thrombectomy catheter was advanced through the 7F sheath in the popliteal vein. Simultaneously, tPA was administered from the catheter tip and the thrombectomy catheter was run (Figure 3). PMT was applied gradually to the thrombosed segments in the superficial femoral, external iliac, and the main iliac veins. The venous patency was assessed with contrast-enhanced control venograms. When the venous system patency was considered insufficient, the procedure was repeated and the maximum venous system patency was aimed to be obtained. After the intervention, all patients were monitored for 24hours in the intensive care unit to observe any emergence of potential complications. All patients continued to receive parenteral anticoagulant therapy after the procedure. The patients were switched to maintenance anticoagulant therapy (low-molecular-weight heparin, warfarin, or a non-warfarin anticoagulant) depending on their clinical course. Temporary filters of the patients were removed within 72 hours at the latest. Patients were seen at follow up visits and anticoagulant therapy they received was reviewed at appropriate time points at the outpatient clinic. After the intervention and at the follow-up visits in the first month, the first year, and the second year; all patients were inquired whether they had any complaints and venous Doppler USG imaging was performed. The mean follow-up duration of the patients was 28 months in our study (Figure 1).

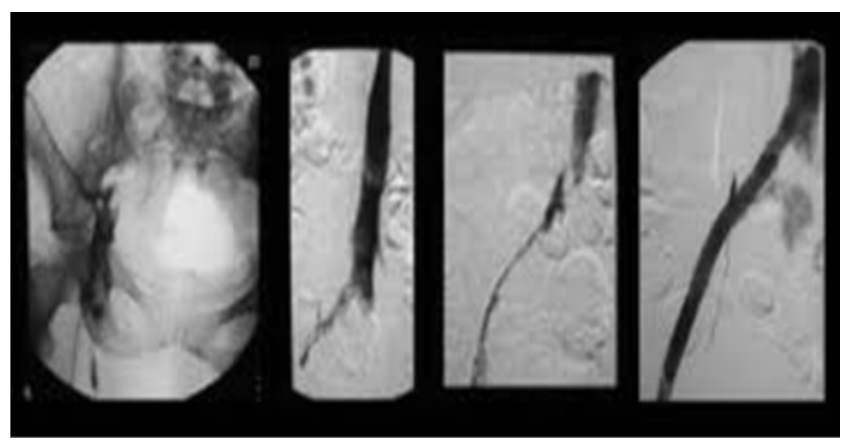

Figure I Venography of some patients when PMT therapy was done.

\section{Statistical method}

Before the statistical analysis, the data were analyzed for conformity with some assumptions. The Kolmogorov-Smirnov normality test was used for testing the data conformity to a normal distribution. The Levene test was used for testing the data conformity with the homogenous variance assumption. After conducting the respective analyses, the statistical tests were selected depending on the characteristics of the data and whether the assumptions were met. Descriptive statistics of continuous and categorical variables were presented as mean \pm standard deviation and as frequency and percentage, respectively. The independent groups t-test was used for the comparison of the continuous variables between the groups. The chisquare test and Fisher's exact test were used for comparing categorical variables when assumptions were met and not met, respectively. The statistical analyses in this study were performed using the SPSS 20.0 statistical package program. The obtained p-values as the results of statistical tests were evaluated at a significance level of $\alpha=0.05$.

\section{Results}

The mean age of the patients was $50.3 \pm 19.8$ years. Of the patients, $11(44 \%)$ were females and $14(56 \%)$ were males. The thrombosed extremity was the left leg in $20(80 \%)$ patients and the right leg in $5(20 \%)$ patients. As for the aetiology; while no aetiological factors were identified in $16(64 \%)$ patients, aetiological factors including immobility, cancer, bone fractures in the extremity, and substance abuse after catheterization or due to substance dependency was identified in $9(36 \%)$ patients. The mean time elapsed from the start of the complaints to the time of intervention was $9.4 \pm 6.8$ days. The thrombus was acute in $11(44 \%)$ patients and subacute in $14(56 \%)$ patients as confirmed by Doppler USG. The descriptive characteristics of the patients; who underwent the intervention, are presented in Table 1.

Table I Descriptive characteristic of the patients

\begin{tabular}{|c|c|c|c|}
\hline \multicolumn{4}{|l|}{$N=25$} \\
\hline Age & & 50 & \\
\hline \multirow{2}{*}{ Gender } & Female & II & $44 \%$ \\
\hline & Male & 14 & $56 \%$ \\
\hline \multirow{2}{*}{ Affected Side } & Right & 5 & $20 \%$ \\
\hline & Left & 20 & $80 \%$ \\
\hline \multirow{2}{*}{ Aetiology } & not-spontaneous & 9 & $36 \%$ \\
\hline & spontaneous & 16 & $64 \%$ \\
\hline $\begin{array}{l}\text { Start of } \\
\text { Complaints(days) }\end{array}$ & & 9,4 & \\
\hline \multirow[t]{3}{*}{ Intervention Success } & $\begin{array}{l}\text { Femoral Vein Patent- } \\
\text { Ilıac Vein no-flow }\end{array}$ & 2 & $8 \%$ \\
\hline & $\begin{array}{l}\text { Femoral Vein Patent- } \\
\text { llıac Vein partial flow }\end{array}$ & 4 & $16 \%$ \\
\hline & Complete patency & 19 & $76 \%$ \\
\hline Hospital stay(days) & & 6,5 & \\
\hline Clnical Improvement in & Near total patency & 18 & $72 \%$ \\
\hline $\begin{array}{l}\text { Second Day of } \\
\text { Intervention }\end{array}$ & $\geq \% 50$ improvement & 7 & $28 \%$ \\
\hline \multirow[t]{2}{*}{$\begin{array}{l}\text { Post-thrombotic } \\
\text { Syndrome }\end{array}$} & No & 18 & $72 \%$ \\
\hline & Yes & 7 & $28 \%$ \\
\hline Venous Reflux & No & 14 & $56 \%$ \\
\hline
\end{tabular}

As for the success of the intervention with venography; complete patency was achieved in $19(76 \%)$ patients, complete patency was achieved in the femoral vein but partial patency was achieved in the iliac vein in $4(16 \%)$ patients, and complete patency was achieved in the femoral vein but no patency was achieved in the iliac vein in $2(8 \%)$ patients out of 25 patients. A factor leading to an unsuccessful outcome was the failure to advance the guide wire beyond the lesion in the iliac vein in one patient. In a patient with substance dependency, adequate 
patency could not be achieved during the procedure. The control computer tomography image of the patient suggested compression on the venous wall due to a rupture-associated hematoma. The length of hospital stay was $6.5 \pm 2.0$ days. The success of the procedure compared to baseline patient complaints was inquired on the second day after the intervention. Almost complete and less than 50\% improvement was found out in $18(72 \%)$ and 7 (28\%) patients, respectively. The second-year Doppler USG imaging as the last assessment revealed no PTS in $20(80 \%)$ patients and mild oedema as a PTS finding in
$5(20 \%)$ patients. The second-year USG imaging revealed the presence or the absence of venous reflux in 14(56\%) and 11(44\%) patients, respectively. The relationship of the intervention success with PTS and venous reflux is presented in Table 2. PTS was present in $84.2 \%$ and absent in $15.8 \%$ of the patients with successful intervention outcome. Of the patients, in whom complete patency was achieved in the femoral vein but partial patency was achieved in the iliac vein as the intervention success; PTS did not develop in $50 \%$ but it developed in the remaining $50 \%$.

Table 2 Descriptive statistics of the variables according to the patients' postop day 2 clinical improvements

\begin{tabular}{|c|c|c|c|c|}
\hline \multicolumn{5}{|l|}{ Clinical Improvement } \\
\hline & & Near total patency $(\mathrm{N}=\mid 8)$ & $\geq \% 50$ improvement $(\mathbf{N}=7)$ & $\mathrm{p}$ value \\
\hline \multirow[t]{2}{*}{ Age } & & $47,4 \pm 20,5$ & $57,7 \pm|7|$, & 0,250 \\
\hline & Female & $9(\% 81,8)$ & $2(\% \mid 8,2)$ & $0,305 * *$ \\
\hline \multicolumn{5}{|l|}{ Gender } \\
\hline & Male & $9(\% 64,3)$ & $5(\% 35,7)$ & \\
\hline & Right & $4(\% 80)$ & $\mathrm{I}(\% 20)$ & $0,564 * *$ \\
\hline \multicolumn{5}{|l|}{ Affected Side } \\
\hline & Left & |4(\%70) & $6(\% 30)$ & \\
\hline & not-spontaneous & $7(\% 77,8)$ & $2(\% 22,2)$ & $0,501 * *$ \\
\hline \multicolumn{5}{|l|}{ Aetiology } \\
\hline & spontaneous & $\mathrm{II}(\% 68,8)$ & $5(\% 3 ।, 3)$ & \\
\hline Start of Complaints(days) & & $8,2 \pm 4,0$ & $16,9 \pm 6,5$ & ${ }^{\mathrm{a}} 0$ \\
\hline Hospital stay(days) & & $6,3 \pm 1,6$ & $7,0 \pm 2,9$ & 0,435 \\
\hline & No & $15(\% 83,3)$ & $3(\% \mid 6,7)$ & ${ }^{\mathrm{a}} 0,043^{*}$ \\
\hline \multicolumn{5}{|l|}{ Post-thrombotic Syndrome } \\
\hline & Yes & $3(\% 42,9)$ & $4(\% 57,1)$ & \\
\hline & No & $13(\% 92,9)$ & $I(\% 7, I)$ & ${ }^{\mathrm{a}} 0,0 \mid 4^{* *}$ \\
\hline \multicolumn{5}{|l|}{ Venous Reflux } \\
\hline & Yes & $5(\% 45,5)$ & $6(\% 54,5)$ & \\
\hline & No & $9(\% 75)$ & $3(\% 25)$ & $0,550 * *$ \\
\hline \multicolumn{5}{|l|}{ Chronic Disease } \\
\hline & Yes & $9(\% 69,2)$ & $4(\% 30,8)$ & \\
\hline & Acute & II (\% I00) & $0(\% 0)$ & ${ }^{\mathrm{a}} 0,007^{* *}$ \\
\hline \multicolumn{5}{|l|}{ Thrombus Age } \\
\hline & Sub-acute & $7(\% 50)$ & $7(\% 50)$ & \\
\hline
\end{tabular}

a(p<0,05), *Chi-Square Test, **Fisher's Exact Test

Of the patients with near-complete patency as the intervention success, venous reflux was present in $68.4 \%$ and absent in $31.6 \%$. Of the patients, in whom complete patency was achieved in the femoral vein but partial patency was achieved in the iliac vein as the intervention success; venous reflux was absent in $25 \%$ but present in $75 \%$. In 2 patients; whom patency was not achieved in the iliac vein, PTS and venous reflux developed.

Characteristics of the variables by the improvement observed on the second day are presented in Table 3. In patients with less than $50 \%$ improvement in their complaints, the emergence of complaints occurred more frequently compared to the patients with a nearcomplete resolution. The frequency of a near-complete resolution was lower with a ratio of $20 \%$ in patients with PTS compared to a rate of $85 \%$ in patients, who did not develop PTS. Of the patients with venous reflux; $45.5 \%$ had a near-complete resolution and the rate of a near-complete resolution was higher with a rate of $92.9 \%$ in patients, who did not develop venous reflux. A near-complete resolution was observed in all (100\%) patients with acute thrombus but it was observed in $50 \%$ of the patients with acute-subacute thrombus. The variables by the presence of PTS are presented in Table 4 . The emergence of complaints occurred at a higher rate in patients with PTS compared to patients, who did not develop PTS. The rate of venous reflux was considerably higher with a ratio of $100 \%$ in patients with PTS compared to a ratio of $30 \%$ in patients, who did not develop PTS. 
Table 3 Descriptive Statistics of Variables According to Presence of Post-thrombotic Syndrome in Patients

\begin{tabular}{|c|c|c|c|c|}
\hline \multicolumn{5}{|c|}{ Post-thrombotic syndrome } \\
\hline & & $\mathrm{No}(\mathrm{N}=18)$ & $\operatorname{Yes}(\mathbf{N}=7)$ & $\mathrm{p}$ value \\
\hline Age & & $51,6 \pm 20,8$ & $47,0 \pm 18,2$ & 0,616 \\
\hline \multirow{2}{*}{ Gender } & Female & II (\%6I,I) & $0(\% 0)$ & ${ }^{\mathrm{a}} 0,007^{*}$ \\
\hline & Male & $7(\% 38,9)$ & $7(\% \mid 00)$ & \\
\hline \multirow{2}{*}{ Affected Side } & Right & $3(\% \mid 6,7)$ & $2(\% 28,6)$ & $0,436 *$ \\
\hline & Left & $15(\% 83,3)$ & $5(\% 7 I, 4)$ & \\
\hline \multirow{2}{*}{ Aetiology } & not-spontaneous & $7(\% 38,9)$ & $2(\% 28,6)$ & $0,501 *$ \\
\hline & spontaneous & $\mathrm{II}(\% 6 \mathrm{I}, \mathrm{I})$ & $5(\% 7 I, 4)$ & \\
\hline Start of Complaints(days) & & $8,6 \pm 4,6$ & $15,9 \pm 6,7$ & ${ }^{\mathrm{a}} 0,005$ \\
\hline Hospital stay(days) & & $6,2 \pm 1,8$ & $7,1 \pm 2,6$ & 0,317 \\
\hline \multirow[b]{2}{*}{ Venous Reflux } & No & $13(\% 72,2)$ & $I(\% \mid 4,3)$ & a $0,014 *$ \\
\hline & Yes & $5(\% 27,8)$ & $6(\% 85,7)$ & \\
\hline \multirow[b]{2}{*}{ Chronic Disease } & No & $10(\% 55,6)$ & $2(\% 28,6)$ & $0,223 *$ \\
\hline & Yes & $8(\% 44,4)$ & $5(\% 7 \mid, 4)$ & \\
\hline \multirow[b]{2}{*}{ Thrombus Age } & Acute & $10(\% 55,6)$ & $I(\% \mid 4,3)$ & $0,076 *$ \\
\hline & Sub-acute & $8(\% 44,4)$ & $6(\% 85,7)$ & \\
\hline
\end{tabular}

${ }^{\mathrm{a}}(\mathrm{p}<0,05)$, *Fisher's Exact Test

Table 4 Descriptive Statistics of Variables According to Presence of Venous Reflux in Patients

\begin{tabular}{|c|c|c|c|c|}
\hline \multicolumn{5}{|l|}{ Venous reflux } \\
\hline & & No & Yes & \multirow{2}{*}{ p value } \\
\hline & & $(\mathrm{N}=18)$ & $(N=7)$ & \\
\hline Age & & $5 I, 4 \pm 21,0$ & $48,9 \pm 19,1$ & 0,766 \\
\hline \multirow[b]{2}{*}{ Gender } & Female & $8(\% 57,1)$ & $3(\% 27,3)$ & $0,135^{*}$ \\
\hline & Male & $6(\% 42,9)$ & $8(\% 72,7)$ & \\
\hline \multirow[b]{2}{*}{ Affected Side } & Right & $3(\% 2 I, 4)$ & $2(\% \mid 8,2)$ & $0,622^{* *}$ \\
\hline & Left & I I $(\% 78,6)$ & $9(\% 81,8)$ & \\
\hline \multirow{2}{*}{ Aetiology } & not-spontaneous & $6(\% 42,9)$ & $3(\% 27,3)$ & 0,420 ** \\
\hline & spontaneous & $8(\% 57,1)$ & $8(\% 72,7)$ & \\
\hline Start of Complaints(days) & & $9,4 \pm 4,3$ & $12,3 \pm 7,8$ & 0,281 \\
\hline Hospital stay(days) & & $6,0 \pm 1,7$ & $7,1 \pm 2,3$ & 0,186 \\
\hline \multirow[b]{2}{*}{ Venous Reflux } & No & $8(\% 57,1)$ & $4(\% 36,4)$ & $0,302 *$ \\
\hline & Yes & $6(\% 42,9)$ & $7(\% 63,6)$ & \\
\hline \multirow[b]{2}{*}{ Chronic Disease } & No & $7(\% 50)$ & $4(\% 36,4)$ & $0,495^{*}$ \\
\hline & Yes & $7(\% 50)$ & $7(\% 63,6)$ & \\
\hline
\end{tabular}

a $(p<0,05),{ }^{*}$ Chi-Square Test, ${ }^{* *}$ Fisher's Exact Test 


\section{Discussion}

The review of the previous studies reported in the literature reveals that PTS develops at a rate of $50 \%$ when patients with iliofemoral DVT are left untreated. Furthermore, the rate of pulmonary embolism has been reported as $4 \%$ in those patients despite treatment. ${ }^{6-8}$ Early thrombolysis supports anticoagulant therapy in preserving the functions of venous valves. ${ }^{8,9}$ Systemic thrombolytic therapy can cause several side effects including uncontrolled bleeding. However, the administration of thrombolytic agents only to the thrombosed segment via catheter-mediated thrombolysis and PMT allowed for the use of low doses minimizing untoward systemic effects. The success of this intervention was reported in the range from $80 \%$ to $90 \%$ with a shortened hospital stay in selected patients. ${ }^{9}$ In our study, $50 \%$ or more venous patency was achieved in $92 \%$ of the patients and no significant complications were observed. During the two-year follow-up of these patients, recurrent DVT was not observed in any patient and venous patency was maintained at the same level in the venous Doppler USG images obtained in the first month, the first year, and the second year. Local or systemic bleeding as the most common side effect of this intervention or clinical pulmonary embolism did not occur in any of our patients.

Bush et al study, using Angiojet on 20 DVT patients as another mode of PMT, reported rapid clinical improvement in $74 \%$ of the patients, and recurrent DVT was observed in the same extremity in 3 patients during the 10-month follow-up period. ${ }^{10}$ Similarly, the study by Gasparis et al. on 14 patients reported that iliac DVT did not recur in any of the patients during the follow-up period of 24 months and that infrainguinal DVT and venous reflux were observed in 3 and 5 patients, respectively. ${ }^{11}$ The study by Rao et al. on 43 patients; to whom PMT was applied, reported that successful thrombolysis was achieved in $95 \%$ of the patients (more than $50 \%$ patency as confirmed by angiography) and that symptoms were regressed in $93 \%$ of the patients. $^{12}$

\section{Conclusion}

PMT should be performed in selected patients; who are young and active patients with acute and/or subacute iliofemoral thrombus formation with the development of phlegmasia cerulea dolens or phlegmasia alba dolens, and who have no contraindications for the procedure. We tested the efficacy and safety of the procedure in this 25-patient series. With PMT applied in one session, near-complete patency was achieved in the venous system without the occurrence of any significant complications in all patients with acute thrombus and $92 \%$ venous patency was achieved in all patients. PMT is an effective mode of treatment in suitable patients in the prevention of late complications, in enabling the patient to return to his/her active life, and in improving the quality of life. The unfavourable aspects of this intervention are that it is not suitable for every patient, it cannot be performed in any centre, and it is associated with high costs.

\section{Acknowledgments}

None.

\section{Conflicts of interest}

All authors declare that there is no conflict of interest

\section{Funding}

None.

\section{References}

1. Robertson L, McBride O, Burdess A. Pharmacomechanical thrombectomy for iliofemoral deep vein thrombosis. Cochrane Database Syst Rev. 2016;11(11):CD011536.

2. Prandoni P, Lensing AW, Prins MH, et al. Below-knee elastic compression stockings to prevent the post-thrombotic syndrome: a randomized, controlled trial. Ann Intern Med. 2004;141(4):249-256.

3. Kahn SR, Shrier I, Julian JA, et al. Determinants and time course of the post-thrombotic syndrome after acute deep venous thrombosis. Ann Intern Med. 2008;149(10):698-707.

4. Vedantham S, Goldhaber SZ, Julian JA, et al. Pharmacomechanical Catheter-Directed Thrombolysis for Deep-Vein Thrombosis. $N$ Engl J Med. 2017;377(23):2240-2252.

5. Kearon C, Akl EA, Comerota AJ, et al. American College of Ches Physicians. Antithrombotic therapy for VTE disease: Antithrombotic Therapy and Prevention of Thrombosis, 9th edn. American College of Chest Physicians Evidence-Based Clinical Practice Guidelines. Chest. 2012;141(2 Suppl):e419S-94S.

6. Sharafuddin MJ, Sun S, Hoballah JJ, et al. Endovascular management of venous thrombotic and occlusive diseases of the lower extremities. $J$ Vasc Interv Radiol. 2003;14(4):405-423.

7. Patterson BO, Hinchliffe R, Loftus IM, et al. Indications for catheterdirected thrombolysis in the management of acute proxima ldeep venous thrombosis. Arterioscler Thromb Vasc Biol. 2010;30(4):669-674.

8. Gogalniceanu P, Johnston CJ, Khalid U, et al. Indications for thrombolysis in deep venous thrombosis. Eur J Vasc Endovasc Surg. 2009;38(2):192198

9. Schweiter J, Kirch W, Koch R, et al. Short and long-term results after thrombolytic treatment of deep venous thrombosis. J Am Coll Cardiol. 2000;36(4):1343.

10. Gasparis AP, Labropoulos N, Tassiopoulos AK, et al. Midtermfollow-up after pharmaco-mechanical thrombolysis for lower extremity deep venous thrombosis. Vasc Endovascular Surg. 2009;43(1):61-68.

11. Reckelhoff KE, Miller A. Interdisciplinary management of deep vein thrombosis during rehabilitation of acute rupture of the anterior cruciate ligament: a casereport. J Chiropr Med. 2014;13(2):121-127.

12. Chaudhry MA, Pappy R, Hennebry TA. Use of the trellis device in the management of deep vein thrombosis: a retrospective single-center experience. J Invasive Cardiol. 2013;25(6):296-299. 